\title{
Birokrasi Pemicu Tindakan Kekerasan: Petugas di Pelabuhan Indonesia
}

\author{
Elfrida Gultom
}

The duty of harbor is very important and it serves services to ships that act activities for instance, goods, passengers, etc. The services in Indonesian harbors tend to be unqualified, high cost economy. Based on the result of the research revealed that the fundamental problems in this context is behavior of involved person in applying the function in harbor, namely corruption, and it implies to reduce state income. The supporting of this phenomenon is birocracy in unqualified services. This condition causes the activities of harbour uncoducively and can not reach the aim to increase national growth economy and prosperous indonesian people.

Kata kunci: pelabuhan, birokrasi, korupsi, jasa, dan kemakmuran

Eung ungsi suatu pelabuhan tidak hanya gagai gerbang (gateway) perdagangan dengan dunia luar, mata rantai (link) arus barang dan jasa, tetapi berfungsi juga sebagai alat penghubung (interface) bagi perdagangan dan perkembangan ekonomi regional maupun ekonomi nasional bahkan internasional. Oleh karena itu semua pelabuhan-pelabuhan di Indonesia dalam mengantisipasi pertumbuhan ekonomi di masa mendatang, diharapkan dapat menangkap semua peluang yang ada, dengan menyiapkan semua fasilitas dan peralatan pelabuhan sesuai dengan permintaan pasar.

Pengelolaan pelabuhan di Indonesia sangat tidak profesional, merujuk pada indikator pelayanan UNCTAD, berdasarkan penelitian LP Universitas Sumatera Utara (USU), ternyata waktu kapal berproduksi (effective time) di pelabuhan hanya berkisar $40-60 \%$. Hal itu diukur berdasarkan tingkat kepuasan pelanggan jasa pelabuhan (port users), yaitu menghitung waktu sejak kapal tiba hingga kapal meninggalkan pelabuhan (Media Republika;2004;4). Ketua Umum DPP INSA Oentoro Surya menilai kinerja pelabuhan tidak pernah maju karena pelayanannya tidak maksimal, dan dipengaruhi oleh kinerja pemerintah yang terlalu birokrat, dan kepentingan pihak tertentu (Bisnis Indonesia; 2005;6). Menurutnya pula, saat ini $50 \%$ dari sekitar 150 pelabuhan internasional di Indonesia inefisiensi dan tak menguntungkan bagi kepentingan ekonomi nasional. Oleh karena itu faktor-faktor penghambat fungsi pelabuhan Indonesia dalam pelayanañjasa 
dianalisis agar dapat diperoleh solusi atau . jalan keluar untuk perigembangan fungsi pelabuhan Indonesia agar lebih maju dan menunjang pertumbuhan ekonomi nasional.

\section{Sistim dan Prosedur atau Uraian Tugas Pelayanan Operasional di Pelabuhan}

Ada beberapa klasifikasi tingkat kepuasan pelanggan (customer satisfaction), yaitu;

1. Sangat puas (exelence service), yakni apabila waktu kerja efektif mencapai 90 $\%$ dan penggunaan waktu kerja selama 12 jam dengan waktu istirahat makan 3 jam. Dalam kondisi ini, pelayanan jasa pelabuhan diberikan sesuai jadwal sehingga kapal tidak terbebani biaya tambahan dan jadwal trayek dapat dipenuhi.

2. Puas (good service), yakni apabila waktu kerja efektif mencapai $80 \%$ dengan penggunaan waktu kerja produktif 18 jam dan waktu istirahat makan dan pergantian shift 6 jam. Koondisi ini tidak terlalu berpengaruh terhadap biaya lebih (extra cost)

3. Tidak Puas (bad service) yakni, apabila waktu kerja efektif mencapai $70 \%$, penggunaan waktu kerja produktif hanya 14 jam. Kondisi ini ada biaya tambahan dan jadwal kapal ke pelabuhan lain terganggu.

4. Sangat tidak puas (poor service), yakni apabila waktu kerja efektif hanya $60 \%$ dan penggunaan waktu kerja produktif hanya 10-13 jam. Hal ini berakibat besarnya biaya tambahan dan terganggunya trayek berikutnya, pada akhirnya ekonomi biaya tinggi tidak dapat dihindari.

Bila dihubungkan antara klasifikasi tingkat kepuasan pelanggan dengan data waktu efektif pelabuhan Indonesia ternyata tingkat pelayanan jasa pelabuhan di Indonesia sangat rendah: Dampaknya ongkos angkut barang (freigt) dengan kapal dari atau ke Indonesia menjadi mahal. Faktor lainnya adalah alat bongkar muat yang sering macet, hasil kerja tenaga lapangan yaitu TKBM dan unsur pengelola pelabuhan yang rendah, ada kerusakan barang sehingga mengakibatkan klaim dari pemilik barang.

Petugas Pelaksana Kegiatan Pelayanan Jasa di Pelabuhan terdiri dari instansi-instansi Pemerintah dan BUMN, yaitu;

1. Bea dan Cukai;

2. Imigrasi;

3. Pelayanan Kesehatan Pelabuhan;

4. Karantina Hewan;

5. Karantina Tumbuh-tumbuhan;

6. Kesatuan Pelaksanaan Pengamanan Pelabuhan (KP3);

7. Instansi Pemerintah Daerah; dan

8. Pengusahaan pelayanan jasa pelabuhan diserahkan pada Badan Usaha Milik Negara yaitu PT (Persero) Pelabuhan Indonesia.

Syahbandar melakukan pengawasan dan pengendalian umum dalam hal pelayanan kapal sejak dari berita kedatangan kapal sampai kapal meninggalkan pelabuhan dengan lancar, aman, tertib, teratur dan selamat.

Uraian pelayanan jasa pelabuhan oleh petugas-petugas di pelabuhan yaitu;

1. Berita Kedatangan Kapal;

a. Distrik Navigasi (Stasiun Radio Pantai) menerima copy master cable dan meneruskannya ke perusahaan pelayaran;

b. Perusahaan Pelayaran

1). Memberitahukan kedatangan kapal paling lambat 1 (satu) hari sebelum kapal tiba di pelabuhan setempat dan 
instansi terkait lainnya;

2). Dilanjutkan . : dengan mengajukan permohonan fasilitas. pelabuhan dan permohonan lainnya yang berkaitan dengan prosedur bongkar/muat dan keluar/ masuk barang, hewan, penumpang, dan ABK kapal pada instansi-instansi terkait.

3). Kantor Syahbandar dan PT. Pelabuhan Indonesia samasamamenyiapkan perencanaan, pelayanan fasilitas labuh/tambat yang dipadukan dengan rencana bongkar/muat barang, hewan serta turun naik penumpang.

4). Kesehatan pelabuhan menerima pemberitahuan rencana kedatangan kapal dari perusahaan/agen paling lambat 1 (satu) hari sebelum kapal di pelabuhan.

2. Kapal Dibawa Menuju Pelabuhan;

Pandu laut membawa kapal masuk mulai dari ambang alur sampai ke dalam pelabuhan atau tempat lain seizing Syahbandar dan Pandu Bandar melaksanakan penyandaran kepal/ labuh dari atau ke dermaga atau juga kolam pelabuhan.

3. Kapal Tiba di Pelabuhan;

a. Kantor Syahbandar mengadakan pengawasan dan pengendalian umum serta menerima warta kapal, menerima surat-surat kapal/buku kapal, memeriksa dokumen kapal, meneliti fisik kapal, menerima pemberitahuan bongkar/muat barang, hewan dan mengadakan persiapan pengawasan terhadap kegiatan bongkar muat; b. Pada waktu kapal tiba di pelabuhan, Kantor Kesehatan Pelabuhan mengadakan pemeriksaan ; oleh instansi lain, dan dillarang menurunkan serta menaikkan orang, barang, hewan dan tumbuhan sebelum pemeriksaan karantina kesehatan selesai.

Menerima permohonan untuk pemeriksaan.

1). Keterangan kesehatan Maritim (Marine Declaration of Health);

2). Hapus tikus (Deratting Certification) atau keterangan bebas hapus tikus (Deratting Exemption Certificate);

3). Daftar ABK;

4). Buku Kesehatan.

c. Karantina Pertanian

1). Karantina Tumbuhan;

a) Mengadakan pemeriksaan

. tumbuh-tumbuhan yang akan dibongkar/muat;

b) Mengadakan fumigasi/ penolakan/pemusnahan/ penahanan pada tumbuhtumbuhan yang mengandung OPTK;

c) Memberi surat pelepasan karantina tumbuhan.

2). Karantina Hewan.

a) Mengadakan pemeriksaan hewan/bahan asal hewan/ hasil bahan asal hewan yang dibongkar atau dimuat.

b) Memberikanpersetujuan / penolakan/pemusnahan / penahanan dari hewan/ bahan asal hewan.

c) Membuat surat kesehatan hewan. 
d. PT. Pelabuhan Indonesia, menyediakan fasilitas pandu, tunda, tambat kapal, dan lain-lain

e. Kantor Imigrasi mengadakan pengawasan, penelitian dan pemeriksaan passportiorang di atas kapal yang datang dari luar negeri

f. Bea dan Cukai

1). Mengadakan pengawasan terhadap kapal;

2). Mencegah adanya penurunan barang dari kapal secara illegal;

3). Mengadakan pemeriksaan fisik di atas kapal dan penyegelan apabila diperlukan;

4). Menerima Pemberitahuan Umum (PU) dari pelayaran selambat-lambatnya pada hari atau jika hari minggu pada hari kedua setelah kapal tiba.

4. Kapal dalam Kegiatan Bongkar Muat;

a. Kantor Syahbandar melakukan pengawasan langsung terhadap kegiatan bongkar muat barang berbahaya dan mengadakan pengawasan kapal secara umum selama kapal berada di pelabuhan, serta mengadakan pengawasan atas kelancaran bongkar muat;

b. PT. Pelabuhan Indonesia mencatat barang yang dibongkar/ dimuat dan memberikan pelayanan kebutuhan fasilitas alat-alat air dan lain-lain serta mengadakan pengawasan dan pencatatan atas penumpukan barang, yang dibongkar atau muat.

c. Perusahaan Bongkar Muat (PBM) PBM melakukan atau melaksanakan kegiatan bongkar muat sesuai dengan petunjuk yang diberikan oleh petugas Kantor Syahbandar. PBM mengadakan pengawasan terhadap pekerjaan TKBM. PBM mengadakan pengawasan terhadap kebersihan akibat bongkar muat dan berkoordinasi dengan PT PELINDO. Pemilik barang atau yang memiliki menyelesaikan urusan dokumen dengan instansi yang terkait untuk mengeluarkan atau memasukkan barang melalui pelabuhan. Sucofindo melakukan survei terhadap barang-barang ekspor yang akan dikapalkan untuk kepentingan ekspor. Bea dan Cukai mengadakan pemeriksaan dan pengawasan barang ekspor dan impor sesuai dengan ketentuan yang berlaku.

d. Tenaga Kerja Bongkar Muat (TKBM)

1). Menerima permohonan permintaan TKBM sesuai format, dari PBM dengan melampirkan fotokopi manifest;

2). Menyiapkan TKBM sesuai pembagian giliran dan mengeluarkan SPK (Surat Perintah Kerja);

3). Bersama-sama dengan petugas PBM melakukan pengawasan demi kelancaran bongkar muat kapal.

5. Kapal akan Meninggalkan Pelabuhan.

a. Dari kapal asing : Surat Kesehatan Pelabuhan

Kantor kesehatan pelabuhan memberikan Health Clearance setelah diadakan penelitian di atas; 

1). Buku Kesehatan;
2). Daftar Awak Kapal;
3). Daftar Penumpang.

b. Bea dän Cukải mengadakan pengawasan pada waktu kapal akan meninggalkan pelabuhan

c. Imigrasi memberikan Imigration Clearance pada crew, list dan passport setelah mengadakan penelitian atas: passport/Seaman Book masing-masing crew atas passport bagi penumpang. Cap keberangkatan pada passport/ Seaman Book. Bagi ABK asing dari kapal niaga dapat menggunakan Seaman Book bila tidak memerlukan passport. Bagi penumpang yang di luar negeri sebelum penumpang turun ke darat, kapal harus menggunakan/ memasang bendera " $\mathrm{N}$ " berdasarkan Toolatings (stb 1949 No. 331) sekarang UU No. 9 Tahun 1992 tentang Keimigrasian.

d. Karantina Pertanian

1). Hewan

a) Mengeluarkan Health $\mathrm{Cer}$ tificate untuk hewan-hewan yang akan dimuat;

b) Meneruskan certificate ini ke kantor ADPEL sebagai clearance dari karantina hewan.

2). Tumbuh-tumbuhan

a) Mengeluarkan surat kesehatan tumbuhan atau makanan bagi yang dimuat atau dibongkar, yang berarti tumbuhtumbuhan atau makanan tersebut bebas dari hama atau penyakit; b) Meneruskan sertifikat ini ke kantor ADPEL sebagai clearance dari karantina tumbuhan.

e. PT. PELINDO

1). Menerima permohonan pandu untuk pemanduan kapal keluar;

2). Mengadakan persiapàn tunda, kepil;

3). Sebelum mengadakan pemanduan kapal keluar, pandu melakukan penelitian terhadap lambung timbulkapal; syaratkapal, muatan kapal dan kemungkinan adanyapelanggaran terhadap peraturan;

4). Apabila dijumpai hal-hal yang membahayakan kapal dan adanya pelanggaran terhadap peraturan, segera melaporkan kepada kantor ADPEL.

f. Syahbandar Pelabuhan

Melakukan Unit Glaring kapal yang meliputi;

1). Melaksanakan penelitian fisik di atas kapai;

2). Meneliti dokumen kapal dan dokumen awak kapal;

3). Mengembalikan dokumen kapal dan dokumen awak kapal;

4). Memberikan Surat Izin berlayar setelah adanya Clearance dari instansi terkait. Kapal berlayar meninggalkan pelabuhan dengan lancar, aman, tertib, teratur dan selamat.

\section{Fakta-fakta pelayanan di lapangan}

Banyak akibat-akibat yang timbul.dari prosedur pelayanan di atas antara lain 
penyimpangan-penyimpangan yang dilakukan oleh pihak-pihak pengelola pelabuhan yang tidak bertanggung jawab mengakibatkan ekoriomi biaya tinggi, karena melakukan pungutan-pungutan yang tidak sesuai dengan peraturan yang berlaku. Yang menjadi permasalahan adalah perilaku tidak terpuji itu dilakukan oleh para aparat yang seharusnya memberantas hai tersebut dan anehnya disetujui oieh pengguna jasa karena merasa pelayanan terhadap kapal dirasakan terialu lama dan cenderung bertele-tele bahkan diada-adakan, pemikiran pengguna jasa, lebih baik memberikan uang tidak resmi tersebut daripada pelayanan akan diperlama, karena bagi perusahaan pelayaran hal itu sangat merugikan.

Keluhan-keluhan banyak berdatangan dari para pengguna jasa pelabuhan, mereka keberatan dengan perlakuan para aparat yang dianggap menyusahkan, namun tidak ada tindakan yang dilakukan oleh Instansi atau lembaga yang menaungi para aparat yang melakukan pelanggaran. Banyak akibat-akibat yang dituai dari perbuatanperbuata pelaku yang melakukan pungutan tidak resmi antara lain;

\section{Mengakibatkan ekonomi biaya tinggi;}

Pungutan tidak resmi yang telah berlangsung bertahun-tahun, membuat harga barang impor yang tiba di pasar lokal naik beberapa persen. Kenaikan harga yang menjadi salah satu faktor ekonomi biaya tinggi ini harus ditanggung oleh konsumen. Adapun putusan produsen dalam negeri yang menaikkan beberapa persen harga pelbagai komoditas untuk ekspor sebagai jalan menutupi biaya tidak resmi, yang pada akhirnya menyebabkan sejumlah barang Indonesia tidak kompetitif, tidak memiliki daya saing kuat, di luar negeri. (Kompas;2002).

\section{Daya saing ekspor Indonesia menjadi rendah}

Masalah ini sangat besar karena pungutan tidak resmi memalukan citra Indonesia di mata dunia khususnya perdagangan Internasional. Sebab eksportirnya akan berasumsi, petugas Indonesia bisa dibeli. Efek asumsi ini bisa kemana-mana.

a). Mengakibatkan pengembangan Pelabuhan Indonesia terhambat; (Suara Merdeka;2004)

b). Pengusaha banyak yang mengalami Kebangkrutan;

c). Proses penerapan keamanan dan ketertiban di pelabuhan terhambat.

Pelayanan pelabuhan dari instansi pemerintahan yang terdiri dari Administrator Pelabuhan; Bea dan Cukai; Imigrasi; Karantina dan Kesehatan Pelabuhan selalu mendapat keluhan dari pengguna jasa kepelabuhanan, terlalu banyaknya birokrasi yang menyebabkan biaya tinggi. Adpel misainya, sejumlah perusahaan pemakai jasa di Pelabuhan Tanjung Priok mengeluhkan pelayanan kantor Adpel yang terlalu lamban memproses dokumen perizinan kapal, sehingga menimbulkan pungutan dalam proses penyandaran kapal di pelabuhan. Hal ini terjadi karena dalam memproses semua urusan administrasi surat menyurat harus melalui Adpel, akibatnya bila pelayanan Adpel kurang memuaskan artinya lambat, maka berakibat pada stagnasi yang mengganggu operasional kapal. (Bisnis Indonesia;2004)

Berdasarkan SE Adpel Pelabuhan Tanjung Priok No. UM.002/12/16 /Adpel. TPK-2004 tanggal 16 Mei 2004, semua urusan administrasi termasuk surat permohonan harus ditujukan kepada Adpel seperti permohonan clearence, Surat Izin Berlayar (SIB), izin operasional yaitu izin 
gerak, izin haluan selatan, izin bongkar barang berbahaya, izin perbaikan kapal (mengelas kapal di dermaga) dan izin lainnya. Kondisi ini menyebabkan banyak antrian dari petugas agen pelayaran menunggu keputusan Adpel yang menyebabkan waktu pelayanan menjadi lebih lama.

Pelayanan Bea Cukai yaitu Sistim EDI sering mengalami keterlambatan sehingga menambah biaya operasional yang besar. Belum lagi kinerja Karantina yang harus meminta biaya tambahan untuk pemeriksaan, padahal sudah menjadi tugas dan fungsinya dan pengguna jasa sudah membayar melalui pajak. Begitu juga Imigrasi yang sering dikeluhkan mencari-cari alasan untuk menyalahkan nakhoda dan $A B K$, hanya untuk mendapat biaya tambahan yang seharusnya tidak demikian. Karantina Kesehatan juga terlalu birokrasi dalam memeriksa dan memberi izin Depkes untuk melakukan impor obat-obatan.

Akibat dari pelayanan yang seperti ini yang dirugikan adalah para penguna jasa dan dampaknya kepada ekonomi biaya tinggi yang akan dibebankan kepada konsumen, di mana harga barang di pasaran menjadi tinggi, bukankah hal ini tidak seharusnya terjadi. Pengertian, pemahaman dan penerapan atas formula-formula indikator performansi atau kinerja pelabuhan harus sama atau seragam diantara pihak-pihak yang terlibat di dalam penyelenggaraan pelabuhan (operator pelabuhan, pemerintah, masyarakat pengguna jasa, dII) agar tidak menimbulkan kerancuan dalam penerapannya sehari-hari terutama mengenai penjabaran dari makna yang terkandung.

\section{Negatifnya Birokrasi di Pelabuhan}

Bahwasanya banyak anggota masyarakat yang lebih suka bertransaksi dengan penegak hukum, menunjukkan bahwa'hukum telah dianggap sebagai suatu komoditi yang dapat diperjualbelikan. Banyak orang mengatakan bahwa ini bukanlah "budaya" dalam arti antropologis, namun apabila perilaku semacam ini telah berpola dan dilakukan berulang kali, sukar untuk mengingkari kenyataan yang buruk ini. Mencari siapa yang menjadi sumber kesalahan tidak mudah karena seperti dalam kegiatan ekonomi, fenomena ini sangat dilandasi pada adanya hukum supply and demand, tanpa adanya kedua faktor ini tidak mungkin terjadi hal demikian.

Birokrasi pada awalnya dibuat untuk mempermudah urusan dan bukan menghambat, namun apa yang terjadi jika birokrasi justru berputar-putar tanpa kendali dan profesionalisme tidak dijadikan indikator utama untuk melihat efisiensi dan efektivitas suatu organisasi (David O; 1997;20). Hal inilah yang merupakan fakta yang menjadi kendala majunya pelabuhan-pelabuhan Indonesia, terlalu banyaknya meja yang harus dilalui untuk bersandarnya kapal dan melakukan kegiatan bongkar muat dan lain sebagainya, padahal yang sangat diperlukan oleh suatu kapal terhadap kinerja suatu pelabuhan adalah efektif dan efisiensi. Namun yang menjadi hambatan bukan saja dari segi fasilitas, sumber daya manusia yang tidak optimal dari hampir di seluruh pelabuhan Indonesia yang mempunyai masalah yang sama, ketidakoptimalan kinerja juga dipicu oleh birokrasi yang berlarut-larut dari segi pelayanan baik oleh fungsi pemerintahan yang terdiri dari beberapa instansi terkait dan fungsi usaha yang dikelola oleh BUMN dalam hal ini PT. Pelindo. Sehingga untuk menikmati suatu pelayanan yang baik dari pelabuhan Indonesia adalah sesuatu yang mahal dan menyebabkan ekonomi biaya tinggi. Hal ini karena begitu melekatnya birokrasi yang 
menyebabkan tumbuhnya praktek KKN yaitu Korupsi, Kolusi dan Nepotisme di tubuh instansi penyelenggara kegiatan fungsi kepelabuhanan di Indonesia.

Berpijak dari fakta-fakta yang telah dipaparkan dalam laporan penelitian kondisi kinerja BUMN dalam mengembangkan fungsi usaha dalam hal ini PT Pelindo dan pelaksanaan fungsi pemerintahan di sektor pelabuhan belum optimal. Hal ini menyebabkan kerugian, sedangkan keuangan negara sangat terbatas. Ditengah globalisasi yang menuntut efektif dan efisiensi kerja yang tinggi agar tetap bertahan ditengah daya saing yang sangat tinggi maka pemerintah mengintervensi BUMN untuk dapat bekerja lebih keras, namun terhambat dengan kualitas manajemen PT Pelindo yang belum memadai, karena terjadi banyak indikasi KKN didalamnya sehingga tidak mendorong kerja yang maksimal dari.PT Pelindo untuk menyumbangkan potensinya yang seharusnya bisa lebih optimal dalam meningkatkan perekonomian nasional (Alloysius; 2003;4).

Kelemahan organisasi pemerintahan, menurut Osborne dan Plastrik, ditandai dengan berkuasanya aspek senioritas terhadap promosi, dan bukan mutu atau kualifikasi. Favoritisme atau kedekatan atasan dan bawahan menggantikan penilaian prestasi objektif, pelanggar disiplin peraturan administrasi tidak diberikan sanksi tegas karena kasihan dan masih terbilang sahabat atau . saudara-saudaranya. Hasilnya adalah organisasi tanpa pertanggung jawaban.

Hal tersebut banyak dijumpai dan tergambar dengan jelas pada banyak departemen pemerintahan, termasuk Badan Usaha Milik Negara (BUMN). Seperti halnya pelaksanaan pelayanan jasa sektor pelabuhan misalnya, banyak dijumpai birokrasi yang berlarut-larut dan sangat keterlaluan sehingga menimbulkan biaya ekonomi tinggi dan menyusahkan pelaku pengguna jasa kepelabuhanan. Hal ini berpengaruh pada citra pelabuhan Indonesia di mata asing, karena heran dengan pola kerja dan birokrasi dari pelayan jasa kepelabuhanan. Mulai dari Instansi pemerintahan dan pengelola pelabuhan sendiri, sistim birokrasi diterapkan, sepertinya ada ungkapan atau peribahasa "kalau bisa dipersulit mengapa dipermudah?".

Banyak BUMN mendapatkan keuntungan bukan disebabkan tingginya tingkat profesionalisme pegawainya, melainkan aspek monopoli penuh, tanpa kompetitor, dan dipenuhi proteksi peraturan dan aspek legalitas foemal lain yang melindungi gerakgerik BUMN. Seperti fakta yang terungkap bahwa dalam menjalankan penyelenggaraan fungsi kepelabuhanan, PT (Persero) Pelabuhan Indonesia melakukan persaingan curang dan monopoli. Contohnya saja di Pelabuhan Tanjung Perak, PT (Persero) Pelabuhan Indonesia mendirikan anak perusahaan yang bergerak di bidang jasa peti kemas, letak kecurangan usaha yang dilakukan adalah, oleh karena PT (Persero) Pelabuhan Indonesia III melayani jasa pelayanan kepelabuhanan berupa jasa pandu, jasa tambat, dan lain-lain kepada kapal yang datang, dalam melayani tugas dan wewenangnya kepada kapal tersebut PT (Persero) Pelindo menawarkan jasa anak perusahaannya yaitu PT Berlian Jasa Terminal yang melayani pembongkaran barang peti kemas milik perusahaan pelayaran tersebut, otomatis menerima karena berhubungan erat dengan faktor yang sangat penting bagi kapal yaitu penyandaran yang secepatnya, bila tidak akan terkatungkatung dan memakan biaya tinggi. Dilema 
tidak sandar cepat dan penawaran yang tidak ada pilihan lain. manyebabkan perusahaan pelayaran tersebut menerima penawaran yang diberikan oleh PT (Persero) Pelabuhan Indonesia III.

Begitu pula dalam penyelenggaraan Tenaga Kerja Bongkar Muat (TKBM) yang dimonopoli oleh Koperasi TKBM yang disetujui berdasarkan SK Dirjen Tiga Menteri yaitu Menteri Tenaga Kerja, Menteri Koperasi dan Menteri Perhubungan. Tentu masih banyak monopoli usaha yang dilakukan oleh pihak terkait dalam menyelenggarakan fungsi pelabuhan untuk kepentingan sekelompok orang dan tidak berorientasi pada kepentingan publik. Profesionalisme sebagai tolok ukur kinerja SDM sering dikesampingkan. Birokrasi berantai sering dijadikan alasan mengapa BUMN dalam melaksanakan kegiatannya tidak lincah, ditambah dengan aspek yang tidak kalah penting bahwa pada kenyataannya hanya sedikit orang profesional yang bekerja pada BUMN. Selebihnya adalah pegawai dan manajer yang hanya berorientasi pada rutinitas kerja dan bukan kreativitas bisnis.

\section{Memangkas Birokrasi melalui Good Coorporate Governance (GCG)}

Penerapan hukum dan sanksi yang berat yaitu pengeluaran aparat yang melanggar harus diwujudkan untuk penertiban dan menjaga citra pelabuhan Indonesia dimata internasional. Seluruh departemen teknis yang berhubungan dan berkaitan dengan setiap kegiatan di pelabuhan lebih baik berkoordinasi, dengan demikian pihak pengguna jasa kepelabuhanan dapat menjalankan kegiatan bisnisnya tanpa harus dibebani birokrasi yang berbelit-belit dan melelahkan apabila tidak memberikan uang tip bagi aparat yang melayani. jasa kepelabuhanan. Sehingga efisiensi dapat tercipta, dan harga-harga barang dapat dijual di pasaran dengan murah. Mekanisme administratif dan fisik hendaknya dilakukan melalui pengawasan yang optimal dari masing-masing departemen.

Salah satu harapan untuk memperbaiki perekonomian indonesia adalah meningkatkan pelayanan kinerja pihak terkait penyelenggara kegiatan pelabuhan, yaitu fungsi pemerintahan dan fungsi usaha. Berkaitan dengan ini fungsi usaha diserahkan pada Badan Usaha Milik Negara (BUMN), dalam hal ini PT.Pelindo yang bergerak di bidang kepelabuhanan. Ironisnya kondisi penyelenggaraan pelabuhan oleh pihak pemerintahan dan pengusahaan pelabuhan oleh BUMN pada saat ini belum dikelola secara baik dan profesional. Padahal semangat reformasi telah mewarnai pendayagunaan aparatur negara dengan tuntutan untuk mewujudkan administrasi negara yang mempu mendukung kelancaran dan keterpaduan pelaksanaan tugas dan fungsi penyelenggaraan pemerintahan negara dan pembangunan, dengan mempraktekkan prinsip-prinsip good govemance. Selain itu, masyarakat menuntut agar pemerintah memberikan perhatian yang sungguhsungguh dalam menanggulangi korupsi, kolusi, dan nepotisme (KKN). Sehingga tercipta pemerintahan yang bersih dan mampu menyediakan public goods and services sebagaimana yang diharapkan masyarakat.

Proses penyelenggaraan kekuasaan negara dalam melaksanakan penyediaan public goods and senvices disebut governance (pemerintahan atau kepemerintahan), sedang praktek terbaiknya disebut good 
govemance (kepermerintahan yang baik). Agar Good Govemance menjadi kenyataan dan sukses, dibutuhkan komitmen dari semua pihak, pemerintah dan masyarakat. Good Governance yang efektif menuntut adanya koordinasi yang baik dan intergritas, profesionalisme serta etos kerja dan moral yang tinggi. Dengan demikian penerapan konsep Good Governance dalam penyelenggaraan kekuasaan pemerintah negara merupakan tantangan tersendiri.

Belum dikelolanya sektor pelabuhan secara maksimal antara lain disebabkan karena tidak adanya pengelolaan tata laksana dan kepemerintahan yang baik yang sebenarnya merupakan cermin dan manifestasi dari aturan hukum, aturan main, dan etika. Kondisi semacam ini dikatakan sebagai ketiadaan Good Governance (Susilo BY; 2004; 17).

Tuntutan perlunya Good Governance juga berpijak pada aiasan bahwa pola-pola lama penyelenggaraan pemerintahan tidak sesuai lagi bagi tatanan masyarakat yang telah berubah. Selain itu pola-pola penyelenggaraan pemerintahan di masa lalu, dimana negara atau pemerintah sangat dominan menjadikan masyarakat menjadi pihak yang sangat diabaikan dalam setiap proses pembangunan. Pemerintah berperan sebagai agent of change, yang dilakukan melalui instrumen kebijakan (policy), perencanaan (planning) maupun anggaran (budget) kemudian dirinci melalui program dan proyek, dan terakhir manajemen implementasi dan pengawasannya. Bahkan pemerintah sekaligus berperan sebagai pelaku. Tatanan dan perangkat yang diperlukan untuk terciptanya good effective governance di tingkat pusat sampai daerah senantiasa periu dikembangkan dan sangat penting dipraktekkan oleh kalangan bisnis melalui prinsip Good Coorporate Governance.
Secara teoretis konsep GCG bukan sesuatu yang baru bagi manajemen korporasi, namun di Indonesia menjadi fenomena baru dalam tata kelola korporasi semenjak pasca krisis tahun 1997 yang lalu. Di satu sisi kita sedang menghadapi era global dan di sisi lain kita sedang dalam situasi krisis. Dalam situasi demikian munculiah kesadaran untuk menyusun suatu struktur, piranti dan mekanisme tata kelola korporasi dan pemegang saham serta stakeholders lainnya. Struktur, piranti dan mekanisme tata kelola korporasi yang baik untuk mencapai goal korporasi itulah yang dikenal dengan sebutan GCG, yaitu suatu sistim pengelolaan korporasi yang mencerminkan hubungan yang sineji antara manajemen dengan pemegang saham, kreditor, pemerintah, supplier dan stakeholders lainnya.

Namun sampai saat ini persoalan yang dihadapi belum sepenuhnya terselesaikan, padahal penetapan pelaksanaan GCG sejak tahun 2003 , misalnya saja pada pelabuhan Tanjung Perak Surabaya. Kerugian-kerugian masih dialami oleh PT. Pelindo. Pembenahan dari kebobrokan yang dihadapi PT. Persero Pelabuhan Indonesia perlu dengan segera dibenahi baik itu dari segi pengeiolaannya dan kinerja yang harus dibenahi dan diperbaiki dan dicari solusi untuk perbaikan tersebut. Karena untuk menghadapi dinamika lingkungan bisnis saat ini ditengah globalisasi, penerapan GCG sebagai pelaksanaan dari setiap perusahaan tidak dapat ditawar lagi. Dalam menerapkan prinsip-prinsip dari GCG PT Pelindo harus memperbaiki dan membenahi kinerja perusahaan, bisa dilakukan dengan mengundang konsultan independen bidang GCG, sehingga akan memaksimalkan nilai perseroan sehingga perusahaan memiliki daya saing yang kuat, baik secara nasional maupun internasional sehingga tercipta iklim 
yang mendukung investasi. Penerapan GCG yang berdasar pada perusahaan yang unggul; kompeten dan berdaya saing secara internasional, tentu memerlukan sumber daya manusia yang profesional, melalui pelatihan-pelatihan dan berkualitas tinggi yang siap bersaing di kompetisi giobal. Program-program kerjasama pelatihan dan pendidikan baik dalam dan luar negeri di berbagai bidang terutama bidang operasional, hukum dan manajemen perlu diadakan, karena pelatihan pendidikan yang beragam tersebut akan memberikan sumbangan yang berharga bagi penyelesaian tugas secara bersama-sama dan seiring. Kesiapan di bidang peralatan, fasilitas dan sumber daya manusia yang baik tentunya akan memampukan dan menyiapkan PT Pelabuhan Indonesia untuk menerapkan pengelolaan perusahaan sesuai dengan prinsip-prinsip dasar GCG. Apabila hal-hal di atas telah tercapai, maka pelabuhan Indonesia siap menjadi kontributor perekonomian negara yang mémpunyai nilai jual yang tinggi dan pada akhirnya menjadi pilar perekonomian nasional yang handal. Penerapan GCG yang menjadi suatu kebutuhan bersama yang sekarang ini banyak dijadikan suatu acuan sebagai prinsip pengelolaan perusahaan modern secara langsung menuntut pada semua pihak yang terlibat dalam usaha kepelabuhanan.

Bagi penyelenggara kekuasaan negara, termasuk yang masuk dalam jajaran birokrasi bidang kepelabuhanan seperti Administrator Pelabuhan; Bea Cukai; Kesehatan Pelabuhan; Karantina dan Imigrasi, nampaknya harus ditekankan bahwà mereka adalah pelayan masyarakat (public servant) yang bertugas untuk memberikan pelayanan yang terbaik untuk rakyat, bukan untuk diri sendiri atau kelompoknya. Apabila dapat diyakinkan bahwa hukum yang dibentuk adalah berorientasi pada kepentingan rakyat dan berkeadilan social, serta penyelenggara kekuasaan negara dalam menjalankan tugasnya bersifat non-diskriminatif, transparan, obyektif dan tegas, mau tidak mau secara perlahan-lahan masyarakat juga akan mengikuti pola ini.

\section{Penutup}

Setiap pelabuhan Indonesia mutlak perlu memegang prinsip efisiensi, yang secara sederhana berarti menghindari segala bentuk pemborosan. Mengingat kenyataan bahwa kemampuan suatu organisasi mengadakan dan memiliki sarana dan prasarana kerja yang juga disebut sumber daya dan dana yang diperlukan untuk menjalankan roda organisasi selalu terbatas, padahal tujuan yang ingin dicapai tidak terbatas, maka tidak pernah ada pembenaran untuk membiarkan pemborosan terjadi. Pengalaman dari berbagai organisasi menunjukkan dengan jelas bahwa banyak faktor penyebab terjadinya inefisiensi; misalnya, pemborosan dapat timbul karena perilaku yang bersifat disfungsional dari para anggota organisasi dan karena ketidaksesuaian pengetahuan dan keterampilan para pelaku daiam menggunakan dan memanfaatkan sarana dan prasarana yang telah dimiliki itu. Hal-hal ini yang harus diperhatikan oleh pelabuhan Indonesia, mungkin telah diterapkan, tapi mengapa masih terjadi pemborosan devisa dan bukan penghematan devisa, dalam arti kapal-kapal nasionalpun enggan menggunakan pelayanan jasa dari pelabuhan-pelabuhan indonesia dikarenakan tidak produktif.

Untuk dapat tercapainya kesamaan pengertian dan penerapan terhadap formulaformula indikator performansi atau kinerja pelabuhan diperlukan tahapan pelatihan atau. 
penyuluhan terhadap semua petugas operasional, secara konsisten dan berkesinambungan. Untuk tercapainya prestasi yang diinginkan, maka terhadap semua pihak yang terlibat dalam penyelenggaraan kepelabuhanan perlu ditentukan besarnya tolok ukur kinerja pelabuhan yang menjadi tanggung jawabnya, sebagai indikasi baik dan buruknya prestasi kerja dari masing-masing pihak yang terlibat sebagaimana yang di sebut diatas.

Rangkaian kualitas tenaga kerja, birokrasi yang handal (aparat pemerintah) dan politisi yang profesional dan mampu menciptakan kebijakan yang kondusif bagi pengembangan daya saing suatu negara. Khususnya bagi jajaran politisi dan birokrasi diperlukan faktor integritas dan jujur yang merupakan prasyarat utama dalam pengembangan daya saing. Semua faktor di atas saling kait mengkait secara simultan untuk menentukan tingkat kompetisi suatu negara..

\section{Daftar Pustaka}

Akuntabilitas dan Good Govemance, Modul Sosialisasi Sistim Akuntabilitas Kinerja Instansi Pemerintah (AKIP), (2000), Yogyakarta:Biro Organisasi SETDA Propinsi DIY.

Alloysius Kiik Ro, Reformasi BUMN via Restrukturisasi dan Privatisasi, Kerjasama Kementerian BUMN UGM - UNLAM,2004, Banjarmasin, 18 September.

David Osborne and Peter Plastrik,(1997) Banishing Bureaucracy: The Five Strategies of Reinventing Government, by USA:Perseus Books Publishing, Asubsidiany of Perseus Books L.L.C.
Harkristuti Harkrisnowo, Good Govemance dan Independensi Birokrasi, Http:/I www. Komisi Hukum.go.id, hal:1

Menteri Pendayagunaan Aparatur Negara, Seminar Naional Sehari Good Government dan Good Coorporate Governance antara Harapan dan Kenyataan, Jakarta, 27 Agustus 2003

Ninyo Pramono, Implementasi GCG dan SCl pada Era Otonomi Daerah, Seminar Sosialisasi Kebijakan Kementerian BUMN, Manado, 25 September 2004.

Pelabuhan Indonesia Merugi, Republika , 14 September 2004, hal:4

Pelayanan Adpel Tanjung Priok dikeluhkan, Bisnis Indonesia, 25 Juni 2004, hal 4

Pengusaha Bongkar Muat di Pelabuhan Gulung Tikar Akibat Banyaknya Pungli, Yahoo. Com, 28 Maret 2003

Pungli Hambat Pengembangan Tanjung Intan, Suara Merdeka, 1 Mei 2004

Pungli Marak di Pelabuhan Tanjung Priok, Aksi, 25 Juni 2004

Pungli Sebabkan Ekonomi Biaya Tinggi, Kompas, 7 Agustus 2002

Sondang P Siagian, Kiat Meningkatkan Produktivitas Kerja, Jakarta: Penerbit Rineka Cipta.

Sponsor Asing Hambat Kinerja Pelabuhan, Bisnis Indonesia, 15 Maret 2005, hal:2 
Birokrasi Pemicu Tindakan Kekerasan Petugas di Pelabuhan Indonesia; Elfrida Gultom

Susilo Bambang Yudhoyono,(2004) Revitalisasi Ekonomi Indonèsia :Bisnis, Politik dan Good Governance, Jakarta: Penerbit Brighten Press.

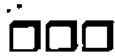

